POLLACK PERIODICA

An International Journal for Engineering and Information Sciences

DOI: 10.1556/Pollack.4.2009.2.11

Vol. 4, No. 2, pp. 107-116 (2009)

www.akademiai.com

\title{
FAULT TOLERANCE STUDY OF SWITCHED RELUCTANCE MACHINES BY MEANS OF ADVANCED SIMULATION TECHNIQUES
}

\author{
Mircea RUBA, Loránd SZABÓ \\ Department of Electrical Machines, Technical University of Cluj \\ 15 Daicoviciu str., 400020 Cluj, Romania, e-mail: Mircea.Ruba@mae.utcluj.ro
}

Received 2 January 2009; accepted 10 February 2009

\begin{abstract}
At the present time an important tendency in industrial automated systems is to apply equipments that can assure uninterrupted operation even if a fault occurs. Advanced electrical drives are complex systems containing both hardware and software. In order to obtain a reliable electrical drive system all its major components have to be fault tolerant. In this paper two switched reluctance machines are studied in order to compare their fault tolerance capability at different stator winding faults.
\end{abstract}

Keywords: Fault tolerance, Switched reluctance machine, Coupled simulation

\section{Introduction}

The concept of fault tolerance emerged in the field of information technology (IT) because of the demand of safety and reliability of a system. Later in more and more fields of engineers tried to design fault tolerant complex systems [1].

A system is the interconnection of components connected together for achieving the same goal: to assure a certain output for a given application. As errors are part of life, the possibility of their appearance in a system must be taken into consideration.

Nevertheless, fault tolerant systems are not easy to achieve. A fault tolerant system must detect faults in its components and also must have the ability either to correct it (for example by switching to a backup unit when the main one fails) or to circumvent it (by reconfiguring the system) [2]. 
Nowadays the tendency in electrical engineering is to develop applications as safe as possible. The interest for fault tolerance concept rises more and more in the researches activity.

Due to electrical power devices that evolved in the last years a combination between electric drives and machines pushed the limits of fault free operation [3]. Any results in this field of fault tolerant devices should be of real interest for specialists working in a great variety of industrial fields.

The switched reluctance machines (SRM) are the cheapest solutions in achieving fault tolerance because they have inherently fault tolerant capability. This ability is due to the magnetic independence of the SRM's phases and the circuit independence of the inverter phases. A fault in either a motor winding or an inverter phase can be relatively easily detected and isolated with no effect on the other phases. Hence the SRM can continue its operation also with one or more phases disabled. Winding fault detectors can indicate the existence of faults, and these can be isolated by intelligent motor controller.

By the improvements in the field of power electronics and also of digital signal processing nowadays, intelligent solutions can be provided in designing a fault tolerant electrical drive system. The separate phase feeding and control of the machines allow an easier approach of the fault tolerant tasks, offering good results [4].

\section{The proposed machines in study}

The first machine in study is a classical $12 / 8$ poles SRM (see Fig 1 a). From this variant emerged a fault tolerant variant having a $12 / 14$ pole structure, as shown in Fig. 1 b. The modifications implied both the rotor structure and the connection of the stator windings.

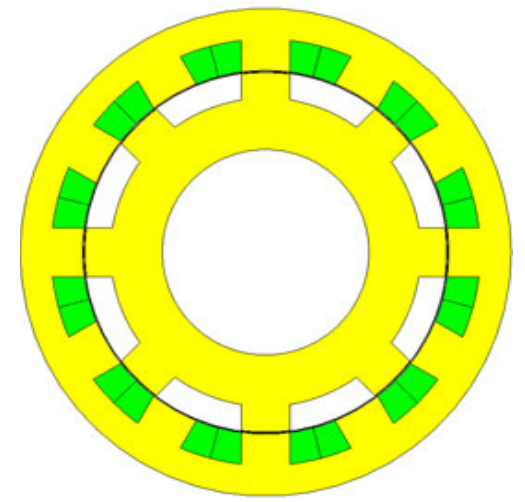

a)

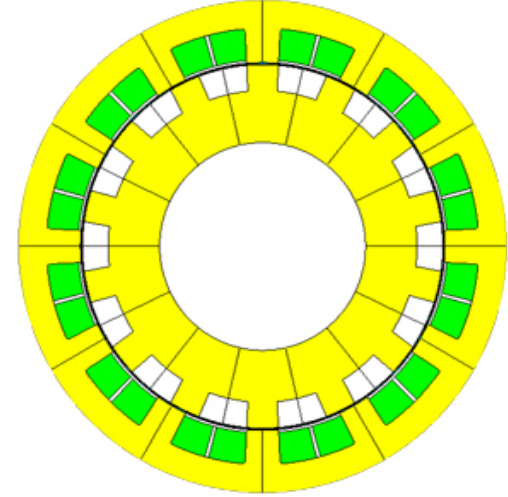

b)

Fig. 1. The two SRMs in study

The winding scheme of the new SRM variant is a six phase duplex type. Practically each phase is split into two channels. At each time two channels, diametrically disposed, are fed. Hence at each moment two pairs of adjacent stator poles are 
contributing to the torque development. In case of a fault on one channel this will not contribute anymore to the torque generation. The second channel connected in parallel is independent of the faulty one and will continue its operation. This winding connection helps the motor to overrun the poles with faulty phases and to minimize the torque ripple.

To emphasize the difference between the two machines in study their flux line distributions should be analyzed (see Fig. $2 a$ and $2 b$ ).

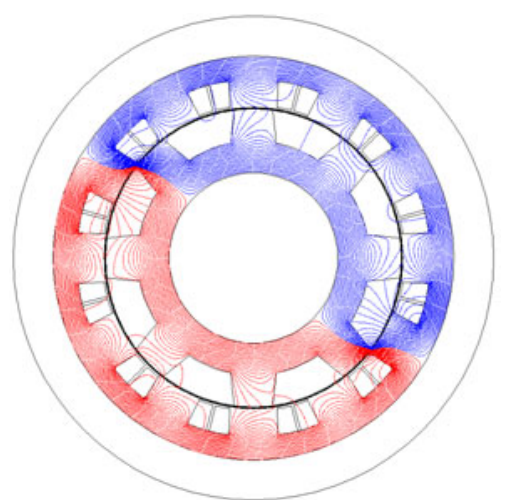

a)

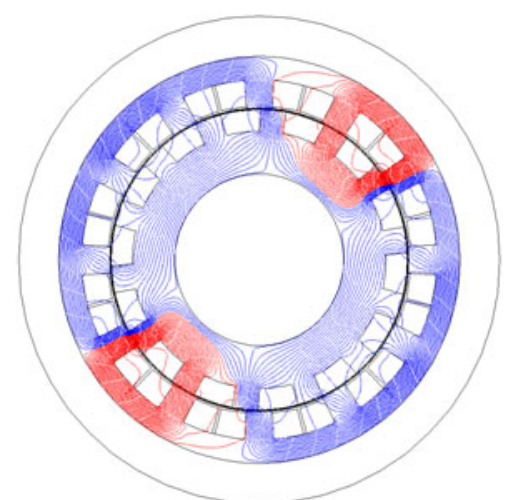

b)

Fig. 2. The flux lines in the two SRMs in study

As it can be seen the novel SRM has shorter flux paths as its classical counterpart, which means it has less iron losses, a major advantage in designing electrical machines.

The 12/14 poles fault tolerant SRM can be fed from the special power converter given in Fig. 3. It has a separate H-bridge circuit for every channel in order to be able to control each one independently, as requested by the fault tolerant design.

A main disadvantage of the proposed 12/14 fault tolerant SRM is its power converter [5]. This is quite complex (having 48 power switches) and has to be able also to detect and isolate the possible converter faults.

\section{The coupled simulation program}

The simulations were performed using the co-simulation technique, by coupling two simulation software packages working together [5]. The machine's models were set up using Cedrat's Flux 2D software package, an advanced finite element method (FEM) based numeric field analysis program [6].

The power converter's structures, for both machines, were built up using Electriflux, the Flux 2D's electrical circuit editor. These are added to the finite elements model of the machines.

As it can be seen in Fig. 4, each channel of one phase is modeled using two electrical coils, corresponding to the 'come and go' sides of the winding [7].

In the electric circuit model the power switches are replaced by resistors. These resistors can be easily controlled from outside the circuit model. For the ON/OFF states 
of the power switches a low $(0.004 \Omega)$, respectively a high value $(100 \mathrm{k} \Omega)$ for the resistance is imposed. Practically the change of the resistance models the opening/closing of the power switches.

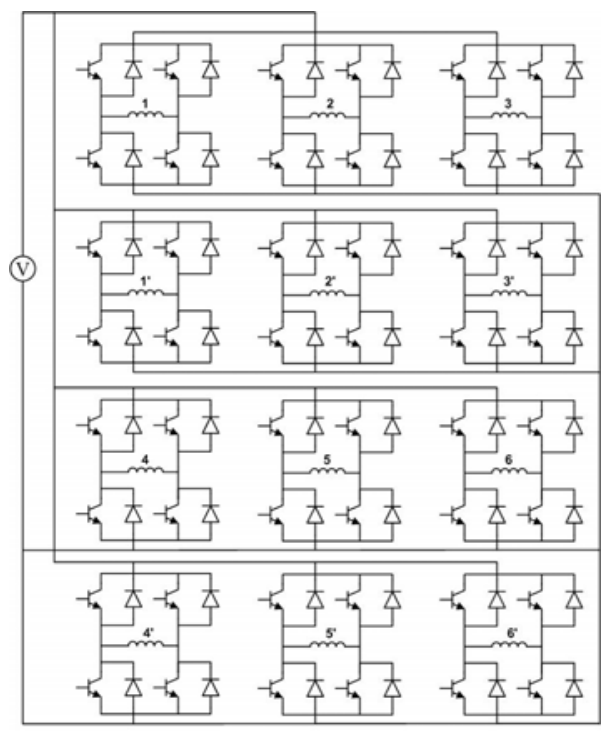

Fig. 3. The converter of the proposed $12 / 14$ SRM

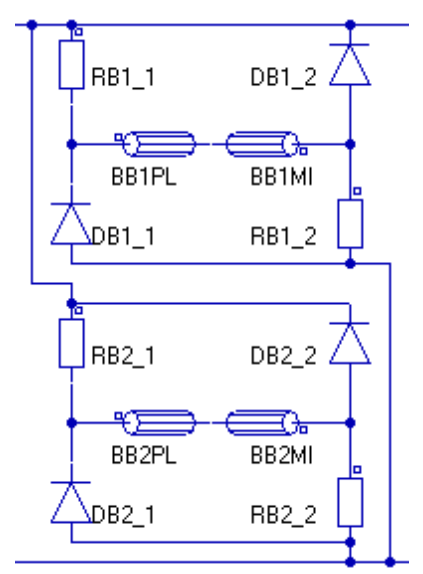

Fig. 4. The electrical circuit model of one phase

The above-mentioned FEM model of the SRM is embedded in the main SIMULINK ${ }^{\circledR}$ program using the advanced FluxtoSIMULINK technique. Practically the FEM model is included in the SIMULINK program via an S-type function. 
At every time step data are exchanged between Simulink and Flux 2D. Several constant parameters, respectively the current and the angular position at each time step are the signals sent to the FEM model of the SRM. The FEM model after the computations performed using the input values is returning to the main program four signals: the phase currents, the electromagnetic torque, the mechanical speed and the angular position of the SRM at that time step.

The main window of the SIMULINK program is given in Fig. 5.

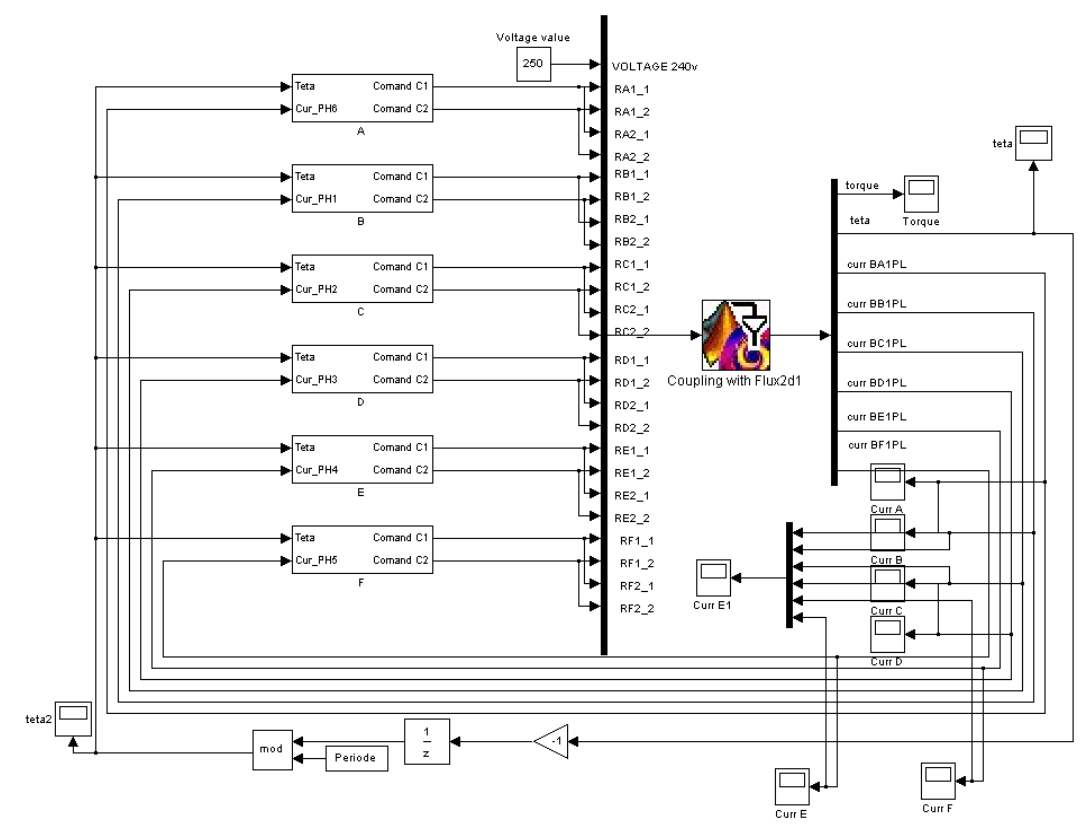

Fig. 5. The main window of the SIMULINK program having embedded the field computation module

By this way Flux 2D thus joined the facilities of MATLAB/Simulink by the Coupling Flux2D S-function type block. The input values of the block (practically the signals to be transferred to Flux 2D) are the resistance values corresponding to each power switch.

The control strategy of the fault tolerant SRM was implemented in the SIMULINK main program.

The power switches are commanded by means of PWM technique. Practically only on one power switch of one phase is controlled by the PWM controller, the second one is held open for the whole conducting period. This means that basically the first modulates the current. The precision of the PWM controller is set by the hysteresis bandwidth around the imposed current [8].

The winding open circuit faults were simulated by imposing OFF state for both switches of the given phase. 


\section{Results of simulation}

The two SRMs in study were simulated under different fault conditions in order to check their fault tolerance capability:

- $\quad$ normal operating mode (reference case);

- $\quad$ open circuit of one channel (faulty case 1);

- $\quad$ open circuit of one phase (faulty case 2);

- $\quad$ open circuit of two channels from different phases (faulty case 3);

- open circuit of one phase and one channel from a different phase (the worst, the $4^{\text {th }}$ faulty case).

In all the cases the previously presented coupled simulation program was tailored for the given machine structure and for the fault conditions in study.

The analysis was focusing on the torque development capability of the SRMs in study under the above-mentioned fault conditions.

For both machines and for all the fault conditions in study the phase currents and the generated electromagnetic torque are plotted versus time.

The results of simulations (the plots of phase currents and of the developed torque versus time) for the 12/8 structures are given in Fig. 6 and in Fig. 7.

As it can be observed in all the above plots, by the increase of the fault's severity the torque ripples are increasing.

In order to compare the fault tolerance capacity of the proposed SRMs at different winding faults the developed mean torques are given in Table $I$.

The simulation results in the case of the proposed fault tolerant 12/14 SRM structure can be seen in Fig. 8 and Fig. 9.

As it can be seen in Table I the fault tolerant 12/14 SRM topology is able to develop torque (around $70 \%$ of the rated torque) and continue its movement even at the most severe fault in study, when one phase and one channel from a different phase is damaged (see Fig. 9c). Obviously the torque ripples are the greatest in this case. Of course heating and force distribution issues limit the operation in this case of fault. For the $12 / 8$ structures for the same fault the torque ripples are substantially greater during the entire simulation time, due to the low number of phases remained healthy.

In the case of the first fault in study, nearly full torque is developed (more then $98 \%$ of the rated value), versus the lower torque from the 12/8 (about 94\%).

The study demonstrated that increasing the number of rotor poles, separating the phases/channels, setting new connections between the existing windings and using a complex control system will provide the best solution for the fault tolerant SRM based electrical drive system.

The coupled model, connecting two programs (FLUX 2D and SIMULINK) fitted excellent to the requirements of the proposed study. The computing power of FLUX 2D thus joined the facilities of SIMULINK in simply describing the different working regimes of the power electronic systems taken into study.

Upon the demands of specific applications, the electrical drive system (both the power converter and the machine) can be optimized and a compromise between fault tolerance level and manufacturing costs can be made. 

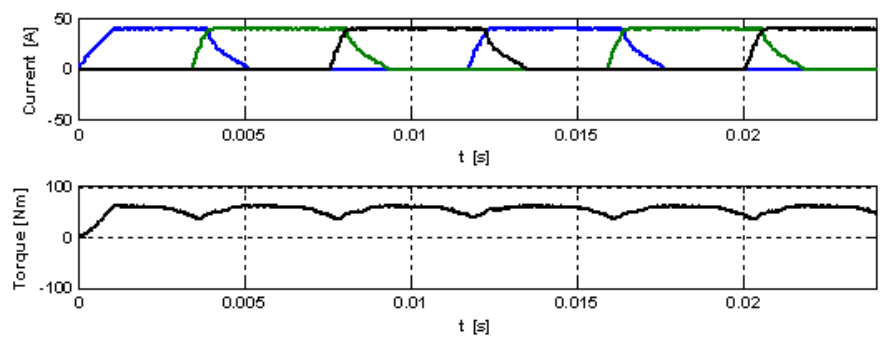

a) normal operating mode
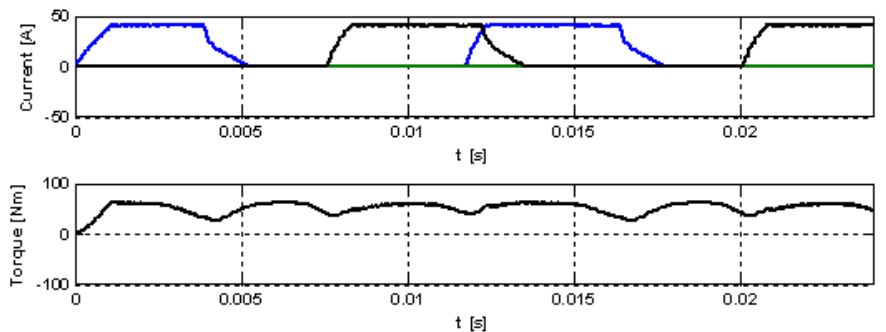

b) one channel open circuit
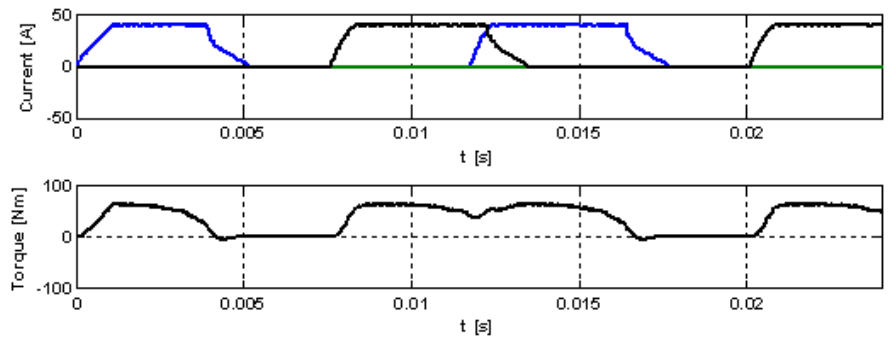

c) one phase open circuit
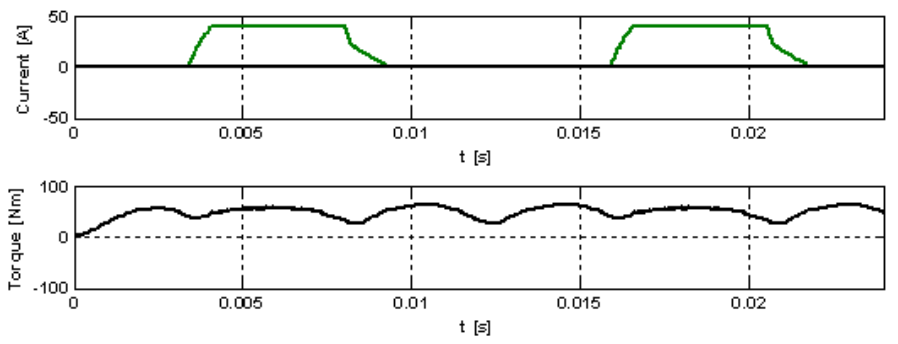

d) two channel open circuit

Fig. 6. Results of simulations for the fault tolerant 12/8 SRM topology

The study was focused on the behavior comparison of two SRM structures and their attached inverters. The torque development capability of the machines was highlighted upon the results obtained via transient simulation of the drive system. 

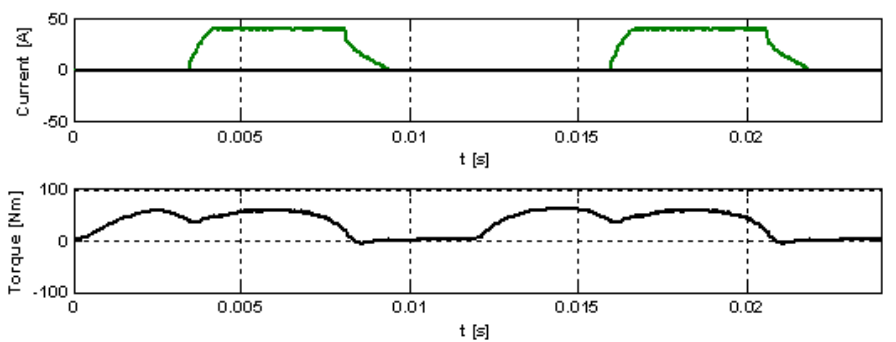

Fig. 7. Results of simulations for the fault tolerant 12/8 SRM topology for one phase and one channel open circuit
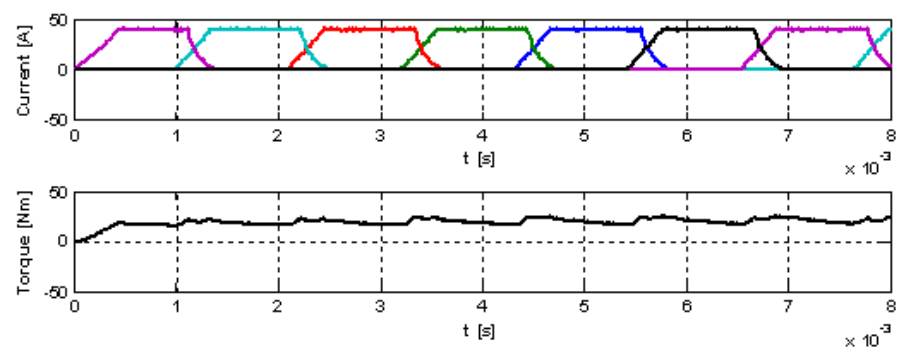

a) normal operating mode
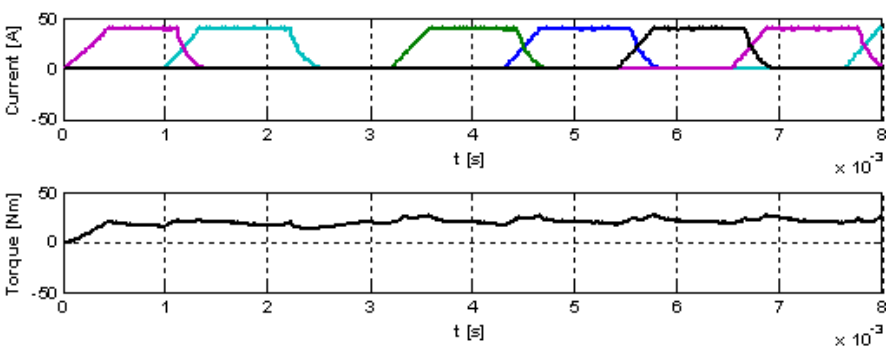

b) one channel open circuit

Fig. 8. Results of simulations for the fault tolerant 12/14 SRM topology

To emphasize an impression regarding the machine's behavior, Table 1 gathers the rated toque development values. As it has been seen, the 12/14 structures are able to serve about $70 \%$ of the rated torque in the worst faulty case. Increase of torque ripples is a natural phenomenon given by the lack of the phase current.

The main disadvantage of the 12/14 fault tolerant SRM is its power converter. This to be also fault tolerant has to be complex, and able to detect and isolate the defects. The inverter (shown in Fig. 3) has 48 power switches and 48 reverse current diodes. Separation of command for each phase or channel should increase the costs.

The main problems during simulations were regarding the computation times. In order to obtain precise results and reasonable computation time the quality of the FEM model's mesh had to be lowered. 


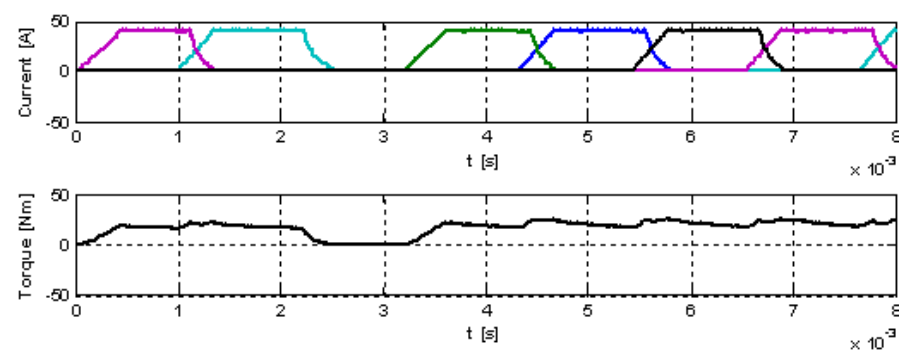

a) one phase open circuit
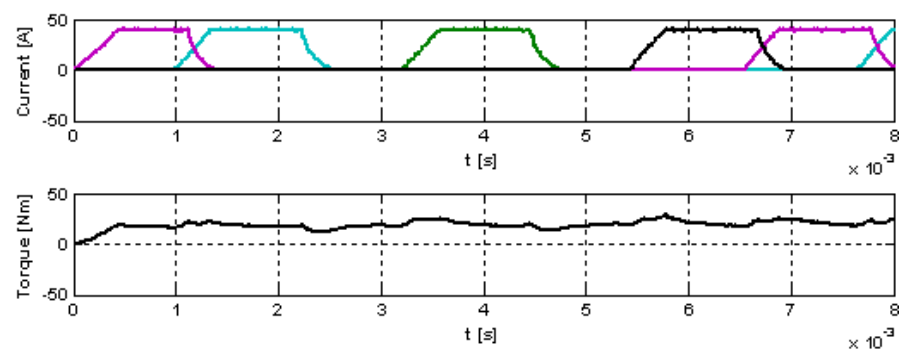

b) two channel open circuit
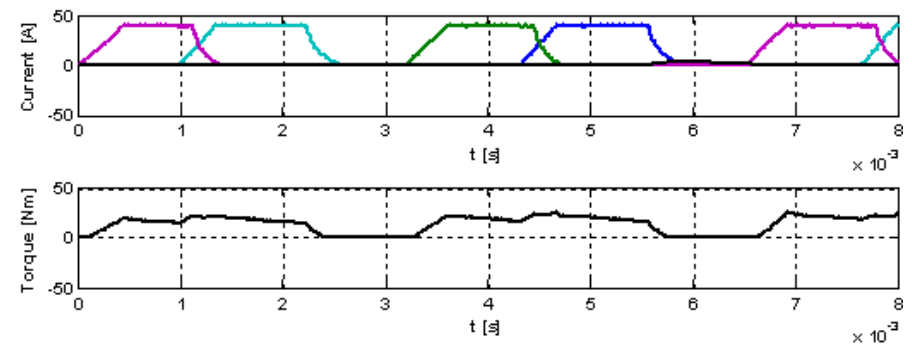

c) one phase and one channel open circuit

Fig. 9. Results of simulations for the fault tolerant 12/14 SRM topology

\section{Conclusions}

It was proved by simulations that the proposed fault tolerant SRM and its converter offer a high level of tolerance to defects. This property added to its low manufacturing costs provides a considerable reason to be used as industrial actuator where safety is critical. According to the imposed tolerance level, the process and the financial allowance, choosing the proper machine-inverter system can be motivated.

Future ideas are regarding changes of the machine geometry, by new placement of the windings. A fault tolerant SRM is intended to build up by using techniques applied in other classes of electrical machines. The structure to be designed in the near future will be a combination of two already existing machines. 
Table I

The mean torques of the SRMs for all the cases taken in study

\begin{tabular}{|c|c|c|}
\hline & Studied cases & $\begin{array}{l}\text { Mean torques }[\mathrm{N} \cdot \mathrm{m}] \\
\text { and percentage of the } \\
\text { rated torque }\end{array}$ \\
\hline \multirow{5}{*}{ 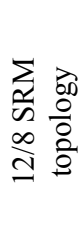 } & Healthy case & $52.21(100 \%)$ \\
\hline & Faulty case 1 & $49.10(94.04 \%)$ \\
\hline & Faulty case 2 & $35.27(67.55 \%)$ \\
\hline & Faulty case 3 & $46.31(88.69 \%)$ \\
\hline & Faulty case 4 & $33.36(63.89 \%)$ \\
\hline \multirow{5}{*}{ 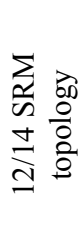 } & Healthy case & $19.93(100 \%)$ \\
\hline & Faulty case 1 & $19.59(98.29 \%)$ \\
\hline & Faulty case 2 & $16.16(81.03 \%)$ \\
\hline & Faulty case 3 & $19.28(96.71 \%)$ \\
\hline & Faulty case 4 & $13.79(69.19 \%)$ \\
\hline
\end{tabular}

\section{References}

[1] Blanke M. Diagnosis and fault-tolerant control, Springer, 2006.

[2] Husain I., Radun A., Nairus J. Fault analysis and excitation requirements for switched reluctance generators, IEEE Transactions on Energy Conversion, Vol. 17, No. 1, 2002, pp. $67-72$

[3] Ertugrul N. LabVIEW for electric circuits, machines, drives, and laboratories, Prentice Hall PTR, 2002.

[4] Heimerdinger W., Weinstock C. A conceptual framework for system fault tolerance, Technical Report CMU/SEI-92-TR-033, Carnegie Mellon University, Software Engineering Institute, Pittsburgh (USA), 1992.

[5] Schlensok C., Hameyer K. Fast structure-dynamic simulation of electrical machines using 2D-3D coupling, Pollack Periodica, Vol. 2, No. 1, 2007, pp. 3-15.

[6] Kovács G., Kuczmann M. Nonlinear finite element simulation for magnetic flux leakage tester, Pollack Periodica, Vol. 3, No. 1, 2008, pp. 81-90.

[7] Szabó L., Ruba M., Fodorean D. Study on a simplified converter topology for fault tolerant motor drives, Proceedings of the $11^{\text {th }}$ International Conference on Optimization of Electrical and Electronic Equipment (OPTIM '2008), Braşov (Romania), 2008, pp. 197-202.

[8] Szabó L., Ruba M., Fodorean D., Simple converter structure for fault tolerant motors, Proceedings of the 2008 IEEE International Conference on Automation, Quality and Testing, Robotics (AQTR '2008) THETA 16, Cluj (Romania), 2008, pp. 244-249. 